\title{
Distinct molecular mechanisms for development of brain asymmetries?
}

\section{Yegor Malashichev}

Department of Vertebrate Zoology, Faculty of Biology, Saint Petersburg State University, Universitetskaya nab., 7-9, Saint Petersburg, 199034, Russian Federation; Laboratory of Molecular Neurobiology, Institute of Experimental Medicine, ul. Acad. Pavlova, 12, Saint Petersburg, 197376, Russian Federation

Address correspondence and requests for materials to Yegor Malashichev, y.malashichev@spbu.ru

\begin{abstract}
Brain and behavioral asymmetries are often associated with neurodevelopmental disorders, but have yet uncovered genetic and developmental mechanisms. A recent study by Vingerhoets and colleagues (2018), published in Brain Structure and Function, examined neural structural and functional asymmetries in a cohort of patients with situs inversus totalis, with and without primary ciliarly dyskinesia as a second diagnosis. The authors showed a potential for independent randomization of handedness, language dominance, and visceral laterality; this provides the first experimental hint that different mechanisms for symmetry breaking and molecular cascades may be involved in producing asymmetry of body and brain.
\end{abstract}

Keywords: brain left-right structural asymmetry, situs viscerum inversus totalis, primary ciliarly dyskinesia, handedness, language dominance, developmental mechanisms, neurodevelopmental diseases.

Citation: Malashichev, Y. 2018. Distinct molecular mechanisms for development of brain asymmetries? Bio. Comm. 63(2): 103-105. https://doi.org/10.21638/ spbu03.2018.201

Author's information: Yegor Malashichev, Ph.D., Associate Professor, orcid.org/00000003-3813-5712

Received: June 05, 2018;

Accepted: June 06, 2018;

Copyright: $\odot 2018$ Malashichev. This is an open-access article distributed under the terms of the License Agreement with Saint Petersburg State University, which permits to the authors an unrestricted distribution and self-archiving free of charge.

Funding: This work was supported by the Russian Science Foundation (Grant No. 14-14-00284).

Competing interests: The author has declared that no competing interests exist.
Some neurodevelopmental disorders of complex or unknown etiology such as schizophrenia, autism spectrum disorder, and speech and language disorders are often associated with an impaired development of functional and structural brain asymmetry (Crow, Done, and Sacker, 1996; Petty, 1999; Robichon, Levrier, Farnarier, and Habib, 2000; Herbert et al., 2005). The direction of the causative link between a somewhat abnormal (reduced or even reversed) brain asymmetry and the diseases is, however, poorly understood. It is unclear whether disruption of normal functional and structural brain asymmetry is a by-product of a disease, or vice versa - differential disruption of brain asymmetry may cause a spectrum of neurodevelopmental abnormalities that are classified as different syndromes. A lack of clear understanding of the genetic background and developmental mechanisms of the phenomena (brain asymmetry and psychosis/dyslexia) complicates the situation (for more discussion, see: Levchenko, Davtian, Petrova, and Malashichev, 2014). The well-known cascades of asymmetricallyexpressed genes with the Nodal in the center of the network, which are responsible for the formation of normal situs of internal organs in vertebrates, are not necessarily all the same as those involved in formation of normal brain asymmetry (Malashichev and Wassersug, 2004; Malashichev, 2006; Sun and Walsh, 2006). Particularly, individuals with situs viscerum inversus do not always show a reversal of brain, handedness, and other behavioral left-right asymmetries. A recent study (Vingerhoets et al., 2018) adds important experimental evidence in support of the existence of distinct mechanisms for development of brain and visceral asymmetries, providing potential insights also into the relationship between them and neurodevelopmental disorders. 
A central role in the transduction of signals and determination of the visceral asymmetries in the vertebral body belongs to a left-sided nodal flow, which is due to ciliary beating at the node during the embryonic neurula stage. The structure of beating cilia in the node lacks the central pair of microtubules (primary cilia) and has a rotational type of movement, and this rotation produces a left-sided nodal flow. Not surprisingly, ciliopathies are sometimes, but not always, accompanied by situs inversus viscerum as a consequence of disrupted primary cilia beating (Davis and Katsanis, 2012; Trulioff, Ermakov, and Malashichev, 2017). On the other hand, proteins associated with the primary cilia may be involved in neurodevelopmental pathogenesis - e.g., Disc1, PCM-1 and AHI1 are linked to schizophrenia; TSC1to autism; PCNT, DCDC2 and Dyx1c1-to dyslexia (see for review: Trulioff, Ermakov, and Malashichev, 2017). Therefore, it would be very important to know whether individuals with the visceral organ situs inversus, who do not show reversal of behavioral handedness, indeed develop visceral reversal due to ciliary dyskinesia. Fortunately, this has recently been tested.

Vingerhoets and colleagues (2018) examined brain structural and functional asymmetries in a cohort of 15 individuals with complete visceral reversal (situs inversus totalis) and found different asymmetry patterns between participants who had $(n=6)$ and didn't have $(n=9)$ primary ciliary dyskinesia $(P C D$, or Kartagener syndrome) as a second diagnosis. In the former subgroup, language lateralization and posterior lobar asymmetry were not affected by visceral inversion; but in the latter subgroup, which showed default language dominance, five out of nine participants were unexpectedly left-handed. Moreover, frontal and occipital lobe petalia torque was only significantly reversed in the subgroup of situs inversus PCD-unrelated individuals. These findings, above all, indirectly support a long-standing opinion of a link between petalia asymmetry and handedness (Lemay and Kido, 1978), but not language dominance. Although Vingerhoets and colleagues (2018) make all the precautions in their conclusions due to a relatively small sample size, it is actually the first experimental evidence explicitly showing (1) that it is unlikely that ciliary movements play a role in the genesis of human brain laterality, and (2) that visceral laterality, brain torque and language dominance may indeed rely on different developmental mechanisms (for more discussion, see: Malashichev and Wassersug, 2004; Malashichev, 2006). These findings can be further supported by earlier evidence of only partial reversal of behaviors in $f$ si (frequent situs inversus) mutant zebrafish (Barth et al., 2005).

These observations and conclusions may have further important consequences for our understanding of abnormal brain development. Indeed, different molecular cascades may regulate not only physiological and structural asymmetries of the brain; the same may be true for neurodevelopmental disorders, e.g., schizophrenia. Recently, we performed a literature survey trying to demonstrate some linkage between ciliary proteins and neurodevelopmental disorders (schizophrenia, autism, dyslexia) based on involvement of primary cilia in the development of brain asymmetry. However, we failed to find any evidence to confirm this hypothesis (Trulioff, Ermakov, and Malashichev, 2017). It seems that broken ciliary proteins affect brain development via neuronal migration, neuritis outgrowth, or interneuron signaling, etc., but not in a way somehow affecting normal functional brain asymmetries. Hence, it is suggestive that those psychotic patients that have broken primary cilia may have less dysfunction in the asymmetry of the brain and a somewhat different clinical course. In contrast, patients with schizophrenia/autism/dyslexia symptoms that demonstrate a stronger disruption of normal functional brain asymmetry may bear mutations in genes that somehow regulate the latter. One good candidate for this is the $\mathrm{WNT} / \beta$-catenin signaling pathway, which is involved both in pathogenesis of, for example, schizophrenia (Singh, 2013; Levchenko et al., 2015) and formation of normal brain asymmetry (Husken and Carl, 2013). Altogether, the study by Vingerhoets and colleagues (2018) may change our conventional thinking that brain and body asymmetry is linked to one or few simple mechanisms, and that those are evidently more diverse and complicated than we previously thought. The same may apply to pathogeneses of neurodevelopmental disorders.

\section{References}

Barth, K. A., Miklosi, A., Watkins, J., Bianco, I. H., Wilson, S. W. and Andrew, R. J. 2005. Fsi zebrafish show concordant reversal of laterality of viscera, neuroanatomy, and a subset of behavioral responses. Current Biology 15(9):844850. https://doi.org/10.1016/j.cub.2005.03.047

Crow, T. J., Done, D. J. and Sacker, A. 1996. Cerebral lateralization is delayed in children who later develop schizophrenia. Schizophrenia Research 22(3):181-185. https://doi. org/10.1016/S0920-9964(96)00068-0

Davis, E. E. and Katsanis, N. 2012. The ciliopathies: a transitional model into systems biology of human genetic disease. Current Opinion in Genetics and Development 22(3):290303. https://doi.org/10.1016/j.gde.2012.04.006

Herbert, M. R., Ziegler, D. A., Deutsch, C. K., O’Brien, L. M., Kennedy, D. N., Filipek, P.A., Bakardjiev, A.l., Hodgson, J., Takeoka, M., Makris, N. and Caviness, V. S. 2005. Brain asymmetries in autism and developmental language disorder: a nested whole-brain analysis. Brain 128(1):213226. https://doi.org/10.1093/brain/awh330

Husken, U. and Carl, M. 2013. The Wnt/beta-catenin signaling pathway establishes neuroanatomical asymmetries and their laterality. Mechanisms of Development 130:330-335. https://doi.org/10.1016/j.mod.2012.09.002

Lemay, M. and Kido, M. 1978. Asymmetries of cerebral hemispheres on computed tomograms. Journal of Computer Assisted Tomography 2(4):471-476 
Levchenko, A., Davtian, S., Petrova, N. and Malashichev, Y. 2014. Sequencing of five left-right cerebral asymmetry genes in a cohort of schizophrenia and schizotypal disorder patients from Russia. Psychiatric Genetics 24:7580. https://doi.org/10.1097/YPG.0000000000000021

Levchenko, A., Davtian, S., Freylichman, O., Zagrivnaya, M., Kostareva, A. and Malashichev, Y. 2015. Beta-catenin in schizophrenia: Possibly deleterious novel mutation. Psychiatry Research 228(3):843-848. https://doi. org/10.1016/j.psychres.2015.05.014

Malashichev, Y. 2006. Is there a link between visceral and neurobehavioral asymmetries in development and evolution?; pp. 33-44 in: Behavioral and Morphological Asymmetries in Veretbrates, edited by Malashichev, Y. B. and Deckel, W. Georgetown, TX: Landes Bioscience.

Malashichev, Y. B. and Wassersug, R. J. 2004. Left and right in the amphibian world: which way to develop and where to turn? BioEssays 26(5):512-522. https://doi. org/10.1002/bies.20036

Petty, R. G. 1999. Structural asymmetries of the human brain and their disturbance in schizophrenia. Schizophrenia
Bulletin 25(1):121-140. https://doi.org/10.1093/oxfordjournals.schbul.a033360

Robichon, F., Levrier, O., Farnarier, P. and Habib, M. 2000. Developmental dyslexia: atypical cortical asymmetries and functional significance. European Journal of Neurology 7(1):35-46. https://doi.org/10.1046/j.14681331.2000.00020.x

Singh, K. K. 2013. An emerging role for Wnt and GSK3 signaling pathways in schizophrenia. Clinical Genetics 83:511517. https://doi.org/10.1111/cge.12111

Sun, T. and Walsh, C. A. 2006. Molecular approaches to brain asymmetry and handedness. Nature Reviews Neuroscience 7:655-662. https://doi.org/10.1038/nrn1930

Trulioff, A. S., Ermakov, A. S. and Malashichev, Y. 2017. Primary cilia as a possible link between left-right asymmetry and neurodevelopmental diseases. Genes 8:48. https:// doi.org/10.3390/genes8020048

Vingerhoets, G., Li, X., Hou, L., Bogaert, S., Verhelst, H., Gerrits, R., Slugzdaite, R. and Roberts, N. 2018. Brain structural and functional asymmetry in human situs inversus totalis. Brain Structure and Function 223(4):1937-1952. https://doi.org/10.1007/s00429-017-1598-5 